\title{
Um estimulante encontro com Michel de Certeau: O feminismo tático de Bertha Lutz
}

\section{Suely Gomes Costa**}

Dos 82 anos de Bertha Maria Júlia Lutz ou, mais simplesmente, Bertha Lutz (*1894+1976), Rachel Soihet recolhe e examina alguns dos atos políticos presentes na trajetória percorrida entre 1919-1937. Dedica-se àqueles que, mais especificamente, lhe sugerem o "feminismo tático" de Bertha Lutz e suas companheiras e que levou à criação da Federação Brasileira pelo Progresso Feminino (FBPF) em 1922, à conquista do voto feminino e, também, a reivindicações feministas no campo dos direitos sociais. Pretende rever, com isso, paradigmas historiográficos construídos entre os anos 80 e 90 do século XX que têm reduzido o peso político dessas manifestações por considerá-las atadas ao tradicionalismo das elites brasileiras. $\mathrm{O}$ texto faz isso propondo um instigante encontro com Michel de Certeau (1994).

A autora soma às páginas do texto "Táticas na conquista de direitos para as mulheres (1919-1937)", um cuidadoso mapeamento de fontes, como a bibliografia produzida por Bertha $e$ aquela escrita sobre ela e os excertos ao livro. São discursos, correspondência, manifesto político, escritos em periódicos diversos, entrevista, artigos e obras de Bertha Lutz oferecidos, generosamente, a seus leitores/as como a instigar novas pesquisas.

\footnotetext{
" Resenha do livro de Rachel Soihet, O feminismo tático de Bertha Lutz. Recebida para publicação em setembro de 2006.

*** Professora do mestrado em Política Social e do Programa de Pós Graduação em História, Universidade Federal Fluminense, Niterói, Rio de Janeiro. suelygom@oi.com.br
} 


\section{O feminismo tático de Bertha Lutz}

(Soihet, 2006:94-129) Em cena, a experiência da educação básica de Bertha na Inglaterra e depois na Sorbonne, em Paris, onde concluirá, em 1917, seus estudos de biologia. Brasileira, filha de pais europeus, nessa quadra de vida na Europa, Bertha se coloca próxima às manifestações feministas, tempo em que desvenda a possibilidade de conquista de direitos através de associações de mulheres. Não está só; lá, conhece Jerônima Mesquita, companheira de ideário. Já em 1918, no Brasil, irá se expressar publicamente a favor das lutas feministas. Concorrendo, é aprovada em primeiro lugar no concurso para o Museu Nacional, em 1919. Como segunda mulher a chegar ao serviço público brasileiro, provoca desconforto e estranhamento público, fato que lhe dá notoriedade. Nada a faz recuar como mostram seus atos políticos. Junta forças políticas e funda, logo depois, a FBPF. Afia suas garras políticas $e$ intelectuais preparando-se para novos embates: em 1933, conclui a Faculdade de Direito do Rio de Janeiro, conhecimento com o qual esgrimirá lutas por direitos. Sem perder de vista contatos feitos em Paris, cria e consolida, posteriormente, outros mais nos EUA, modos externos de reconhecimento aos movimentos desencadeados no Brasil, de apoiar-se e de tornar palatável e irreversível a chegada das mulheres ao espaço público. Eleita deputada, seu curto mandato entre 1936 e 1937, perdido com a instauração do Estado Novo, a impulsiona. Rachel Soihet seleciona circunstâncias que movem Bertha Lutz pelo voto feminino, mas não só. Seus atos expõem muito mais que a objetivação do voto feminino: são seguidas as iniciativas pela conquista de direitos políticos para as mulheres no Brasil e ainda a confirmação de sua presença na arena científica onde acumula saberes sobre botânica, biologia e organização de museus, ações profissionais exercidas no Museu Nacional, percurso sobre o qual mais pesquisadoras vêm se debruçando. (Souza et alii, 2005) Este livro, sem pretensões biográficas, prefere indicar pistas e traçados de maior (e menor) nitidez, deixando um conjunto de sugestões úteis às revisões de conhecimentos sobre o feminismo da primeira onda. Sublinha lutas do século XIX nas 
quais mulheres brasileiras, antes de Bertha, em especial Nisia Floresta e Josefina Álvares de Azevedo, dentre tantas abolicionistas e feministas e outras que se empenharam na chegada das mulheres ao mundo público. Morando tantos anos no exterior, Bertha teve encontros decisivos com mulheres de seu tempo, não deixando margem de dúvida quanto a sua plena identificação com o feminismo e suas lutas. Rachel Soihet, como historiadora atenta aos processos culturais, traz à baila a multiplicidade de tempos vividos por essa jovem mulher, em seus deslocamentos do Brasil para a Europa, de seus encontros com feminismos de terras distantes (Inglaterra, França e América do Norte), situando a interpenetração de códigos culturais que aproxima jovens brasileiras das lutas feministas fora do país. É de se lembrar o caso emblemático de Mary Wollenstonecraft, cujas idéias de igualdade entre os sexos, em fins do século XVIII, inspiram a brasileira Nísia Floresta nas primeiras décadas do XIX. (Floresta, 1989) Trata-se de algo que também pode ser observado em suas pesquisas recentes sobre militantes e conjunturas entre 1970 e 1980, período em que a segunda onda feminista se adensa e avança no Brasil. (Soihet \& Copio, 2006; Delphy, 1994; Pinto, 2003) Outrora como hoje, tempos de alargamento coexistem com os de restrição de fronteiras de circulação feminina com recuos $e$ retomadas de lutas por igualdade entre os sexos. Os atos políticos de Bertha e de outras mulheres de seu entorno, selecionados por Rachel Soihet, evidenciam o terreno movediço em que são enunciados, anunciados e conduzidos, daí a noção de "feminismo tático", criando "ocasiões" para a conquista de metas e objetivos. Não são atos domesticados, ainda que bem comportados. A autora localiza circunstâncias nas quais estão se dando os avanços por direitos dos feminismos europeus, mas registra também as restrições a tais avanços no Brasil com seus diversos graus de intensidade e impactos locais. Nesse "feminismo tático", ganha especial interesse a dialética dos tempos históricos presentes na vida cotidiana e nos encontros locais e internacionais de homens e mulheres de terras distantes - lembrando Marshal Sahlins - em 
diferentes conjunturas e espaços. (Sahlins, 1990) Quando Rachel releva os sete anos de Bertha na Inglaterra, onde conclui sua formação, lembra-nos tempos de ruídos feministas que a atraem. Ao sublinhar, ainda, as restrições de sua mãe quanto a qualquer aproximação com esses movimentos, por sua condição de menor de idade e de estrangeira, parece falar da experiência de um tempo de silêncios também vivido. Quando situa Bertha como auxiliar do pai no preparo de obra científica, remete a um tempo de estímulos, de uma conduta masculina nem sempre comum no Brasil. Mostra Rachel, na existência em foco, a experiência desses tempos plurais e de muitos sentidos em que os atos políticos se fazem. Por isso mesmo, seu livro polemiza noções usuais $e$ largamente propagadas na historiografia dos feminismos que criticam a maneira "tradicionalista" de Bertha $e$ suas companheiras da FBPF conduzirem suas lutas.

Duas obras publicadas em 1981 e uma de fins dos anos 90 merecem a atenção de Rachel. As de 1981 são de June Hahner, pesquisadora norte-americana e de Branca Moreira Alves, militante da segunda onda feminista. Revendo esses textos, podese perceber que, com diferentes graus de intensidade, essas autoras abordam o feminismo de Bertha Lutz e suas companheiras, em geral, mulheres das camadas médias e altas, no interior de matrizes analíticas que presidiram estudos políticos no Brasil em tempos de redemocratização do país. Assim, as questões apontadas por Rachel Soihet permitem iluminar paradigmas disseminados amplamente nos anos 80 , sobre o tradicionalismo das elites brasileiras, não apenas no que tange aos feminismos, mas aos movimentos sociais em geral. De fins dos anos 90, Rachel Soihet examina a contribuição de Susan K. Besse, autora que aponta para a persistência da noção que associa Bertha Lutz e suas companheiras a condutas políticas que serviram "para fortalecer e legitimar a nova ordem burguesa, em que pese a conquista de alguns direitos", porém, com uma significativa ressalva: "as táticas desenvolvidas pela FBPF foram cuidadosamente adaptadas ao contexto em que a organização 
operava". Trata-se de uma primeira aproximação da noção explicitada por Rachel.

O texto original de Michel de Certeau discute as táticas de consumo, úteis para pensar os atos políticos, inclusive os dos feminismos em geral e, em especial, o de Bertha Lutz e de tantas mulheres de seu tempo. Os feminismos, tão plurais, são produtos culturais; têm-se transformado a cada tempo e espaço. Sua circulação num dado ambiente sempre se viu diante de processos culturais que, conforme Certeau (1994:44-45), articulam conflitos e legitimam, deslocam ou controlam "a razão do mais forte". Os feminismos se desenvolvem sob tensões e, muitas vezes, violências. Daí, "equilíbrios simbólicos, contratos de compatibilidade e compromisso mais ou menos temporários". Lembra Certeau que as táticas do consumo, "engenhosidades do fraco para tirar partido do forte, vão desembocar então em uma politização das práticas cotidianas". Práticas cotidianas dos feminismos também ofertam produtos culturais em meio a grandes batalhas na guerra contra as desigualdades. Lançam mão de estratégias e táticas, aproveitando, racionalmente, ocasiões para objetivação de desejos e projetos. Disso não escapa a experiência em tela. A moderação, a aproximação dos poderosos e tantas práticas confundidas com as de domesticação, no caso, são também armas de lutas, mostram Rachel e Certeau. No campo político, porém, há mais motivações e automatismos sociais por conhecer, nem sempre atos racionais. Eles também nos movem homens e mulheres - como sujeitos da história, em culturas postas como lugares de embates na redefinição de processos sociais de diversos sentidos civilizadores e tempos simultâneos. Lemos esse livro pensando em tudo isso; junto com ele, nos chegam mais e mais sugestões analíticas nessa empreitada em marcha: a revisão historiográfica dos femininos no Brasil. 
O feminismo tático de Bertha Lutz

\section{Referências bibliográficas}

CERTEAU, Michel de. A Invenção do cotidiano. Artes de fazer. Petrópolis, Vozes, 1994, [Tradução: Ephraim Ferreira Alves].

DELPHY, Christine. Feminismo e Recomposição da Esquerda. Revista Estudos Feministas, vol.2, n³, Rio de Janeiro, CIEC-UFRJ, 1994.

FLORESTA, Nísia. Direitos das mulheres e injustiça dos homens. $4^{\mathrm{a}}$ ed. São Paulo, Cortez, 1989.

PINTO, Céli Regina Jardim. Uma história do feminismo no Brasil. São Paulo, Editora Fundação Perseu Abramo, 2003.

SAHLINS, M. Ilhas de história. Rio de Janeiro, Zahar, 1990 [Tradução: B. Sette].

SOIHET, R. O feminismo tático de Bertha Lutz. Florianópolis/Santa Cruz do Sul, Editora das Mulheres/EDUNISC, 2006.

e COPIO, Flávia E. O Centro da Mulher Brasileira (CMB) e suas experiências nos anos 1970-1980. In: FERREIRA, Jorge e REIS, Daniel A. (orgs.) As esquerdas no Brasil. 2006 (no prelo).

SOUZA, Lia Gomes Pinto de; OLIVEIRA, Mariana Moraes de; LOPES, Maria Margareth. Para ler Bertha Lutz. Cadernos Pagu (24), Núcleo de Estudos de Gênero - Pagu/Unicamp, jan-jun 2005, pp.315-325. 